\title{
Shear Strength of Reactive Resistance Welded Ti6Al4V Parts with the Use of Ni(V)/Al Multilayers
}

\author{
ŁUKASZ MAJ, JERZY MORGIEL, KRZYSZTOF MARS, ANNA TARASEK, \\ and ELŻBIETA GODLEWSKA
}

The Ti6Al4V/(Ni/Al)/Ti6Al4V joints were obtained through reactive resistance welding which takes advantage of electric current heating to initiate the rapid exothermic reaction of $\mathrm{Ni}(\mathrm{V}) / \mathrm{Al}$ multilayers and activate diffusion of elements across the Ni/Al-Ti6Al4V interfaces. Simulations of temperature distribution, carried out using $\mathrm{COMSOL}^{\circledR}$ software, showed temperature gradient in the joint being a result of differences in resistivity of the Ti6Al4V alloy and the $(\mathrm{Ni} /$ $\mathrm{Al}$ )/Ti6A14V interface. Shear tests revealed that extending duration of the process from 2 to 6 minutes helped to improve the shear strength from $\sim 240$ to $\sim 335 \mathrm{MPa}$. The microstructure observations of the samples after those tests showed that de-cohesion of the joint occurred along the filler material/base material interface. A microcrack network characteristic for reacted $\mathrm{Ni} / \mathrm{Al}$ foil with small ridges was found on the flat surfaces of fractured samples.

https://doi.org/10.1007/s11661-018-4843-5

(C) The Author(s) 2018

\section{INTRODUCTION}

WELDING of titanium-based alloys, like a Ti6Al4V, poses a significant challenge due to a high affinity of titanium for oxygen as well as its high melting temperature. The former may be overcome by applying an argon protective atmosphere, while the latter by a local heating with an electron or a laser beam. ${ }^{[1]}$ The strength of obtained joint is therefore compromised not only by a coarse grain present in melted and solidified material, but also by a large heat-affected zone softened by recovery processes. On the other hand, diffusion brazing process is most frequently performed at temperature below the $\alpha \rightarrow \beta$ transition at $\sim 1000{ }^{\circ} \mathrm{C} .{ }^{[2]}$ However, it requires relatively long processing times necessary to activate the solid-state diffusion across the interface between filler material and base material. ${ }^{[3]}$ Therefore, new alternative techniques of joining titanium alloys are still sought.

Reactive metallic multilayer foils, releasing a large amount of heat during self-propagating high-temperature synthesis (SHS), open new possibilities in joining materials. Initiated by an external energy pulse, they

ŁUKASZ MAJ, JERZY MORGIEL, and ANNA TARASEK are with the Institute of Metallurgy and Materials Science, Polish Academy of Sciences, 25 Reymonta St., 30-059 Kraków, Poland. Contact e-mail: 1.maj@imim.pl KRZYSZTOF MARS and ELŻBIETA GODLEWSKA are with the Faculty of Materials Science and Ceramics, AGH University of Science and Technology, 30-059 Kraków, Poland.

Manuscript submitted February 23, 2018.

Article published online July 27, 2018 produce fast local temperature raise (even up to $1500{ }^{\circ} \mathrm{C}$ for the $\mathrm{Ni}(\mathrm{V}) / \mathrm{Al}$ system $^{[4]}$ ) and results in the melting of at least one of reactants. However, the heat released at fast moving SHS front is insufficient to melt surfaces to be joined. Up till now, obtaining a firm connection with the use of reactive multilayers has been possible only either through deposition of an additional braze alloy coating $^{[5]}$ or by supporting the heat pulse produced during SHS reaction in other ways. ${ }^{[6]}$ The approach taking advantage of braze alloy good wetting properties has been already applied by commercializing NanoFoil ${ }^{\circledR}$ product. It consists of freestanding $\mathrm{Ni}(\mathrm{V}) / \mathrm{Al}$ multilayer foil covered with Incusil ${ }^{\mathrm{TM}}(\mathrm{Ag}-\mathrm{Cu}-\mathrm{In}-\mathrm{Ti})$ alloy Ignited $\mathrm{Ni}(\mathrm{V}) / \mathrm{Al}$ multilayer releases enough heat to melt the $\mathrm{Ag}-\mathrm{Cu}-\mathrm{In}$-Ti layer, securing good wetting of pieces of titanium alloy. It was reported that such a joint can be obtained in a very short time, but its shear strength barely reaches $\sim 40 \mathrm{MPa} .{ }^{[5]}$ The other way is realized by passing strong electric currents through elements to be joined with multilayers, what helps to attain high-temperature activating diffusion processes necessary for good connection. Therefore, this joining process is called a 'reactive resistance welding' (RRW). Although not fully worked out as yet, theoretically it should secure not only fast but also much stronger connection, compared with the brazing technique.

The RRW method was originally applied to join elements made of refractory metals, including tungsten and tantalum with the use of reactive powders ignited with a pulse of $1000 \mathrm{~A}$ electric current. ${ }^{[]]}$However, due to problems with handling of powders and their spreading in a layer of same thickness, new filler materials like Ni/Al multilayers are tried. ${ }^{[6]}$ Application 


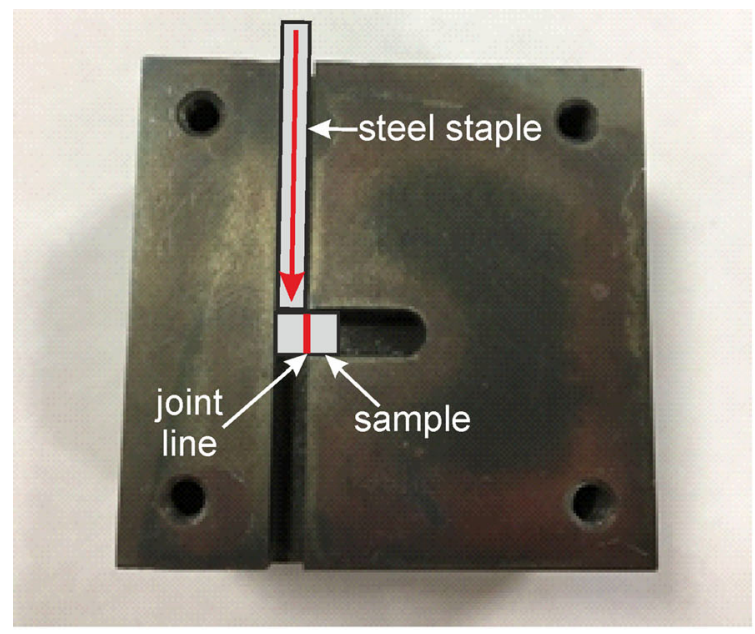

(a)
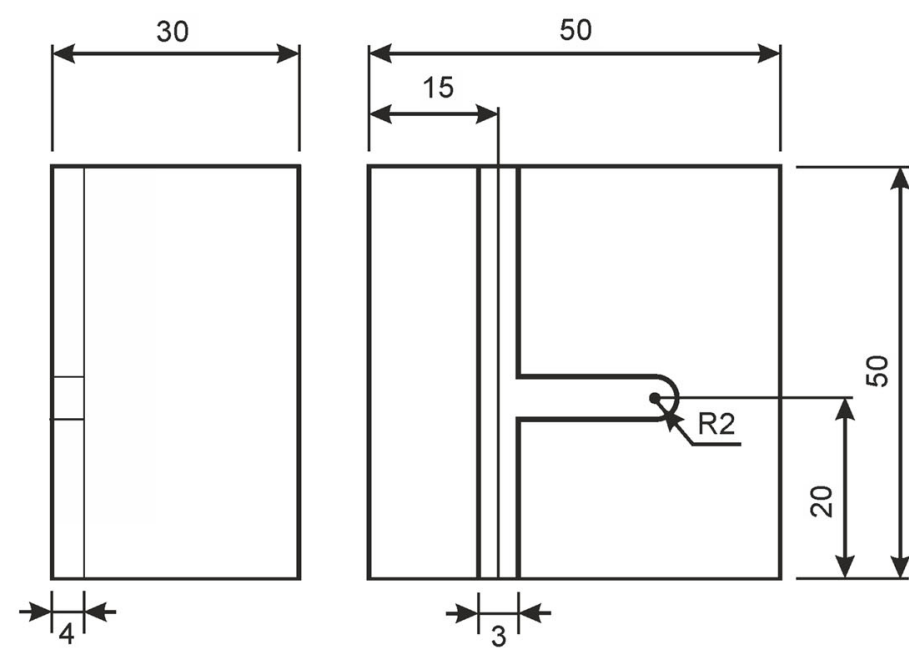

(b)

Fig. 1-Image of a die used in shear strength measurements $(a)$ and its dimensions in $\mathrm{mm}(b)$.

of the reactive multilayers instead of powders not only allowed to reduce the thickness of the filler material from $\sim 1 \mathrm{~mm}$ to $<100 \mu \mathrm{m}$, but also to lower the electric current down to $400 \mathrm{~A}$. Simultaneously, it helped to alleviate the high-temperature exposure of the joined elements. Microstructure and hardness of the Ti6Al4V/ $\mathrm{NiAl} / \mathrm{Ti} 6 \mathrm{Al} 4 \mathrm{~V}$ joints after 2, 4, and 6 minutes of processing time were already described, ${ }^{[8]}$ but no measurements of their strength were reported as yet.

Therefore, the main objective of the present study was to investigate the shear strength and topography fracture of Ti6Al4V parts joined with $\mathrm{Ni}(\mathrm{V}) / \mathrm{Al}$ multilayers by the RRW method. The microstructure observations of fractured surfaces were carried out with the use of scanning electron microscopy (SEM).

\section{MATERIALS AND METHODS}

The two-phase $(\alpha+\beta)$ Ti6Al4V alloy was cut into $5 \mathrm{~mm} \times 5 \mathrm{~mm} \times 3 \mathrm{~mm}$ platelets with a diamond wire saw. Freestanding $\mathrm{Ni}(\mathrm{V}) / \mathrm{Al}$ multilayer foils with a nominal period of $\Lambda=50 \mathrm{~nm}$ and overall thickness of $60 \mu \mathrm{m}$ were used as a filler material. All samples were ground and polished with abrasive papers and colloidal silica suspension, respectively.

A dedicated stand described in detail elsewhere ${ }^{[6]}$ was used in the RRW joining experiments. Each Ti6Al4V/ (Ni/Al)/Ti6Al4V stack was placed in a chamber (evacuated down to $10^{-1}$ mbar) between steel staples under a load of $100 \mathrm{MPa}$. A DC current of $400 \mathrm{~A}$ was passed through the samples for 2, 4, and 6 minutes. The temperature of the joint was measured using a type-K thermocouple $(\phi \sim 0.5 \mathrm{~mm})$. The temperature gradient in the joint area was simulated with the help of COMSOL $^{\circledR}$ software, with the input data being the resistivity of the Ti6Al4V alloy $\left(\rho_{\text {Ti6Al4V }}=1.78 \times\right.$ $\left.10^{-6} \Omega \mathrm{m}\right)$ and the measured resistivity of the Ti6A14V/NiAl interface $\left(\rho_{\text {Ti6Al4V/NiAl-interface }}=5 \times\right.$ $\left.10^{-5} \Omega \mathrm{m}\right)$.
Shear strength of the obtained joints was examined in a static axial compression test on INSTRON 3382 testing machine using a die dedicated for small samples as presented in Figure 1(a). The hardened low-carbon steel die $(50 \times 50 \times 30 \mathrm{~mm})$ had two channels. The vertical channel served as a guiderail for the steel staple, while the short horizontal $(4 \times 4 \mathrm{~mm})$ one helped to fix the Ti6Al4V/(Ni/Al)/Ti6Al4V joint (Figure 1(b)). The shear strength measurements were carried out at room temperature $\left(22^{\circ} \mathrm{C}\right)$ at a crosshead speed of $0.2 \mathrm{~mm} /$ min. For each bonding time, five samples were tested.

The microstructure observations of fractured samples after shear test were carried out with the use of Philips XL30 scanning electron microscope operating at $30 \mathrm{kV}$ in backscattered (BSE) and secondary electrons (SE) modes in order to obtain an information about the crack path and the fractured surface topography, respectively.

\section{RESULTS}

Temperature in the middle of the $\mathrm{Ti} 6 \mathrm{Al} 4 \mathrm{~V} /(\mathrm{Ni} / \mathrm{Al}) /$ Ti6A14V joint was approximated by a signal averaged from an area of $\sim 0.5 \mathrm{~mm}$ in diameter (as marked by dashed circle in Figure 2(b)). A flow of 400 A DC current resulted in a fast temperature raise up to $\sim 700{ }^{\circ} \mathrm{C}$ within 30 seconds and initiation of the SHS reaction already at $\sim 240{ }^{\circ} \mathrm{C}$, which is evidenced both by the presence of a small hump on the temperature vs. time curve and simultaneous emission of a bright orange light in the $\mathrm{Ni}(\mathrm{V}) / \mathrm{Al}$ multilayer foil. Extending the RRW time to 6 minutes caused slow increase of the maximum attained temperature up to $\sim 760{ }^{\circ} \mathrm{C}$. Simulations, taking into account exclusively the effect of current flow, revealed that the highest temperature is reached at the joint center with a steep gradient on both sides (Figure 2(b)). The obtained results indicated that the filler material was heated up to $\sim 800{ }^{\circ} \mathrm{C}$, whereas the temperature of the joined elements was lower than $770{ }^{\circ} \mathrm{C}$ at a distance exceeding $0.5 \mathrm{~mm}$. 


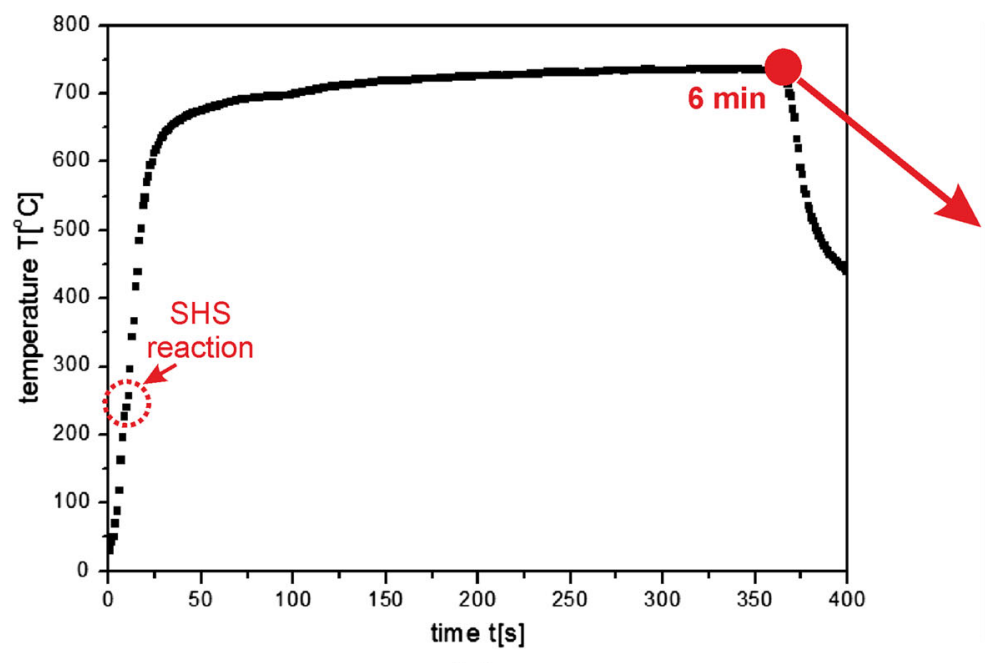

(a)

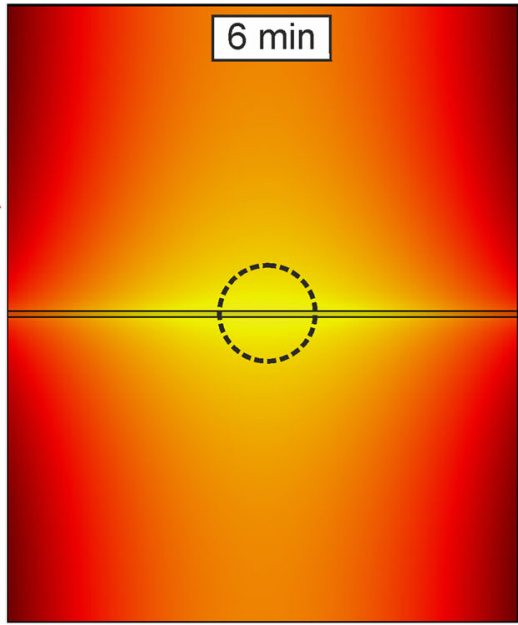

(b)

Fig. 2-Temperature measured during RRW of Ti6Al4V/(Ni/Al)/Ti6Al4V stack $(a)$ with corresponding temperature simulation after 6 min of process time $(b)$.

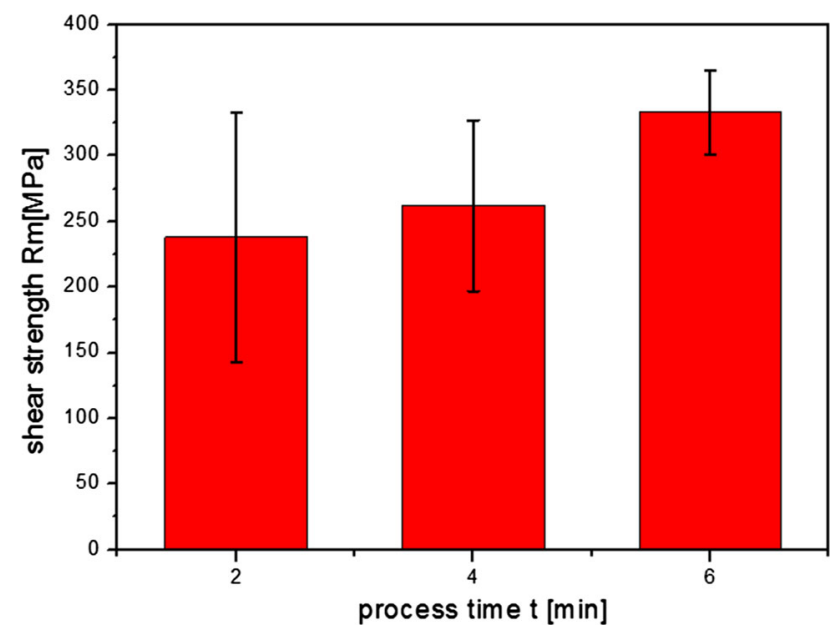

Fig. 3- Shear test of Ti6Al4V/(Ni/Al)/Ti6Al4V joints fabricated in 2,4 , and $6 \mathrm{~min}$.

The results of shear tests showed that passing the $400 \mathrm{~A}$ of DC current through the Ti6Al4V/(Ni/Al)/ Ti6Al4V joints for a longer time improved the shear strength from $\sim 240$ to $\sim 335 \mathrm{MPa}$ (39.5 pct of increase) (Figure 3). The strength mean value estimated for the shortest process time (2 minutes) had a standard deviation close to $95 \mathrm{MPa}$ (as individual results varied from 130 to $380 \mathrm{MPa}$ ), due to less perfect connection between $\mathrm{NiAl}$ filler and surfaces of adjoining platelets. For longer process times, i.e., 4 and 6 minutes, the pressed Ti6Al4V pieces get more exposure to high temperature what caused their local softening (especially in the near surface area) and secured better contact with filler material. As a result, the standard deviation of the average shear strength was tightened down to 55 and $32 \mathrm{MPa}$ for 4 and 6 minutes, respectively.

The SEM/BSE observations of the fractured Ti6Al4V/(Ni/Al)/Ti6Al4V joints revealed that crack propagation during the shear test occurred predominantly within the diffusion zone frequently shifting between surfaces of NiAl filler material and Ti6Al4V base alloy (Figure 4(a)). Simultaneously, the reacted filler material close to fracture path showed an extensive crumbling out (see white arrows in Figure 4(a)). A scheme of crack propagation, taking into account all the above, is presented in Figure 4(b). The SEM/SE observations of topography of fractured samples showed presence of the cracks formed during solidification of the filler material as well as locally periodical waves crested with small ripples documenting the non-steady mode of propagation of SHS reaction front (Figure 4(d)). Additionally, small areas with lighter contrast in Figure 4(c) give evidence that at least small pieces of the NiAl/Ti6Al4V diffusion zone are broken out, if not part of Ti6A14V itself.

\section{DISCUSSION}

The RRW method relies both on the heat generated within the joint area by SHS reaction of the filler $\mathrm{Ni} / \mathrm{Al}$ multilayer and electric current heating of the joint and the rest of the platelets. A good connection between the platelets is in this case of critical importance as it should eliminate any voids in the joint area facilitating inter-diffusion between filler material and Ti6Al4V alloy.

The simulated temperature distribution at the Ti6Al4V/(Ni/Al)/Ti6Al4V joint area showed that near to the filler material it is indeed higher than that of Ti6Al4V base plates. Formation of the temperature gradient can be attributed to the higher resistance at the Ti6Al4V/(Ni/Al) interfaces compared with the Ti6Al4V alloy. It is a result of the porosity present between the filler material and base Ti6Al4V components, also observed in our previous work. ${ }^{[8]}$ These nano-voids may appear due to the fast solidification of the filler material, accompanied by its contraction and 


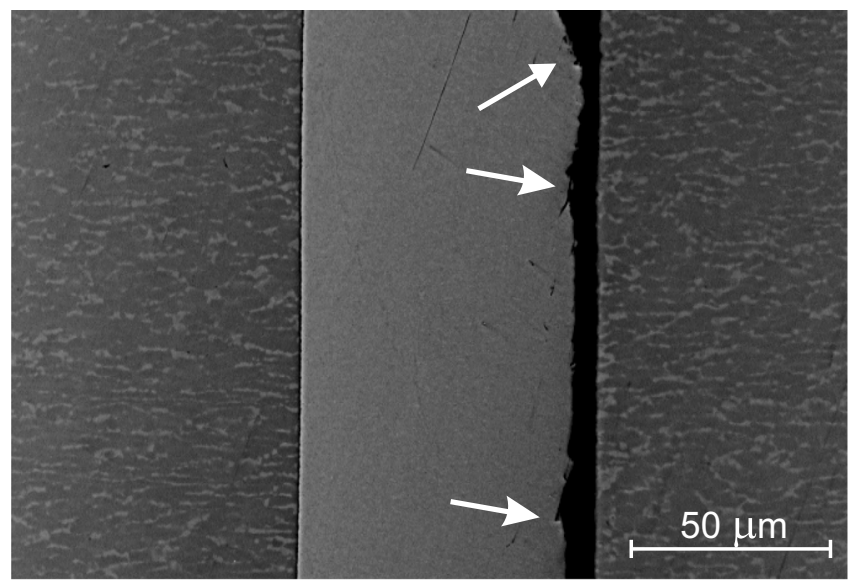

(a)

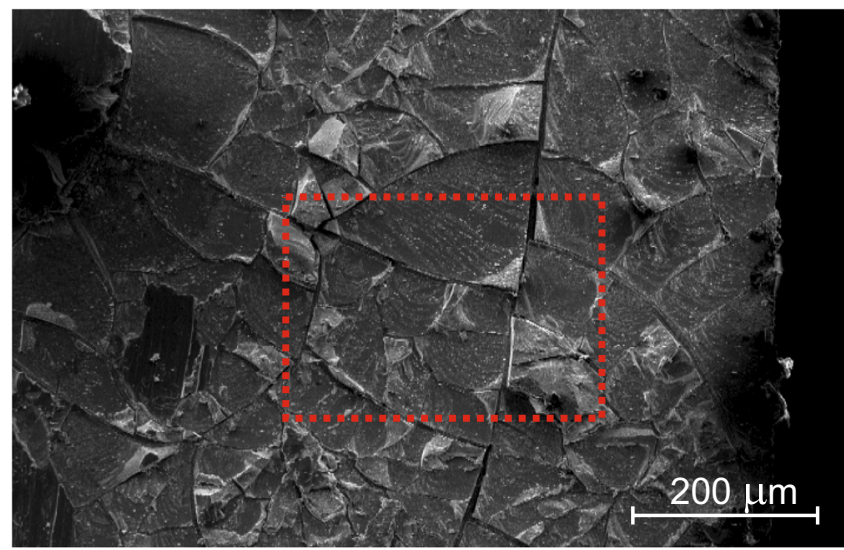

(c)

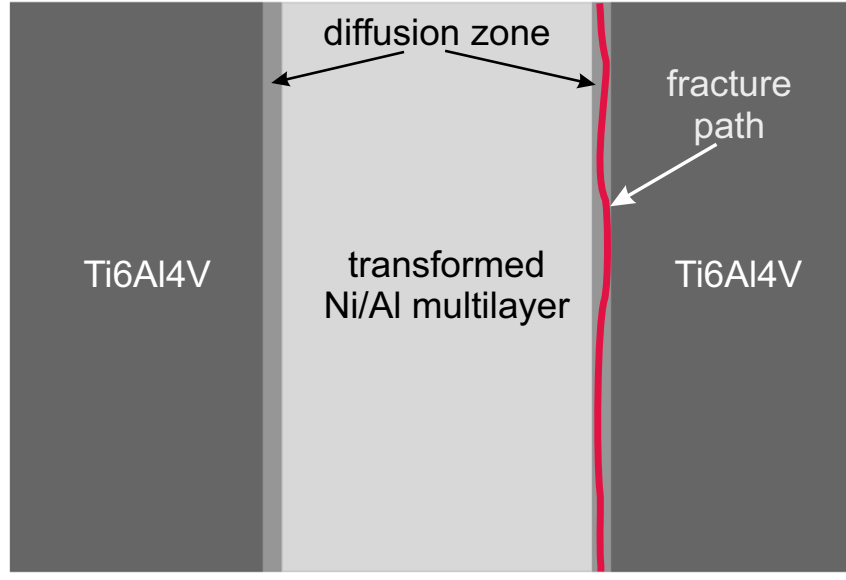

(b)

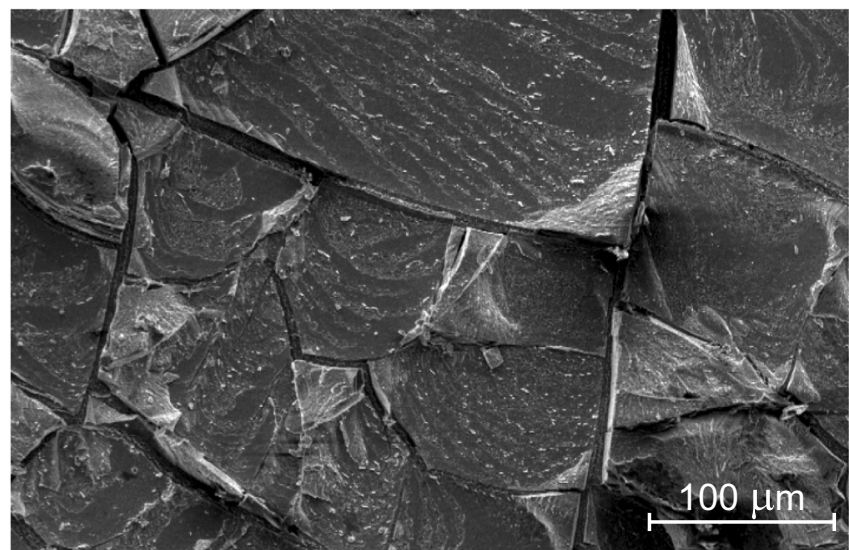

(d)

Fig. 4-SEM/BSE image of section of fractured Ti6Al4V/(Ni/Al)/Ti6Al4V joint after shear strength test $(a)$, scheme of fracture path $(b)$, and $\mathrm{SEM} / \mathrm{SE}$ images of surface topography of fractured joints $(c, d)$ (white arrows in (a) point out to crumbled out material).

macroscopic shape change. Thus, even a large load applied to the $\mathrm{Ti} 6 \mathrm{Al} / \mathrm{V} /(\mathrm{Ni} / \mathrm{Al}) / \mathrm{Ti} 6 \mathrm{Al} 4 \mathrm{~V}$ stack during joining process may not provide a full matching between joined surfaces. Simultaneously, the temperature of the joining process controlled by electric current was so adjusted as to not exceed the temperature of $\alpha \rightarrow \beta$ transition $\left(\sim 1000{ }^{\circ} \mathrm{C}\right)$ in Ti6Al4V alloy, i.e., in order to preserve its initial mechanical properties. In case of friction welded Ti6Al4V parts even area $1 \mathrm{~mm}$ away from the weld interface may be affected by a temperature exceeding $1000{ }^{\circ} \mathrm{C}$, significantly changing the microstructure and degrading mechanical properties of obtained joint. ${ }^{\left[{ }^{9]}\right.}$ On the other hand, diffusion bonding of TiAl alloys with the $\mathrm{Ni}(\mathrm{V}) / \mathrm{Al}$ multilayers reaction proceeded through solid state diffusion. ${ }^{[10,11]}$ This process, carried out in vacuum furnace, results in uniform heating of all components to be joined. However, the heat of exothermic reaction of $\mathrm{Ni}(\mathrm{V}) / \mathrm{Al}$ multilayers is practically lost due to long processing time. In view of above, the RRW is a unique process capable of producing a temperature gradient utilizing all available heat sources exactly in the most needed area. In this way, it accelerates the diffusion in the joint with simultaneous preserving mechanical properties of base material as presented in Reference 8 .

Mechanical properties of the joints are evaluated mostly through their shear strength. Present experiments showed that the maximum strength of Ti6Al4V/(Ni/Al)/ Ti6A14V joints reaches $\sim 380 \mathrm{MPa}$. The main cause of failure of produced joints, especially those obtained after shortest processing time (2 minutes) were the still numerous voids present at the interface between Ti6Al4V alloy and SHS-reacted Ni/Al multilayer. For the longer times, local flow of the Ti6A14V platelets helps to close at least some of these defects, what explains the rise of the shear strength. The latter measured for RRW joined Ti6Al4V/(Ni/Al)/Ti6Al4V parts turns out to be $\sim 10$ times higher than for similar joints obtained with NanoFoil ${ }^{\circledR}$ brazing initiated by short current pulse $(9 \mathrm{~V} / \sim 1 \mathrm{~s}),{ }^{[5]}$ i.e., practically without any additional heating. However, diffusion bonding of titanium alloys using $\mathrm{Ni} / \mathrm{Al}$ multilayers indicates that shear strength higher than $300 \mathrm{MPa}$ is achievable only when the processing time is relatively long ( $>60 \mathrm{~min}-$ utes). ${ }^{[10]}$ It indicates that the RRW process has an advantage in time-temperature scale over the currently 
applied methods of materials joining with the use of reactive $\mathrm{Ni} / \mathrm{Al}$ multilayers.

The knowledge of crack propagation path and the characteristic features of fractured surfaces in the joint usually help both to classify the formed connections as well as to improve their strength. Shearing forces applied to $\mathrm{Ti} 6 \mathrm{~A} 14 \mathrm{~V} /(\mathrm{Ni} / \mathrm{Al}) / \mathrm{Ti} 6 \mathrm{Al} 4 \mathrm{~V}$ joint resulted in their failure within the diffusion zone formed between Ti6Al4V base material and reacted multilayer foil, i.e., one of the most frequent cases for welded material. However, in case of presently investigated RRW joints most of flat cleavage areas are crisscrossed with a set of perpendicular cracks resulting from the shrinkage occurring during NiAl solidification. The areas located near the cracked edges carried patches of material evidently differing in contrast, which have been pulled out from diffusion zone or even from the Ti6Al4V alloy. All of it indicates a quasi-brittle cracking mode, bearing also features of some plastic deformation. The observations carried out by Simoes et al. ${ }^{[10]}$ for diffusion bonded TiAl alloys revealed that the joint characterized by a strength of $\sim 300 \mathrm{MPa}$ cracked in similar way, except for the lack of the network of perpendicular cracks, which is specific for $\mathrm{Ni}(\mathrm{V}) / \mathrm{Al}$ multilayers reacted by SHS. The results obtained for other methods of joining of Ti6A14V alloys like laser beam welding with niobium interlayer revealed fully brittle cracking during shear tests being a consequence of hydrogen and oxygen contamination of weld pool. ${ }^{[12]}$ The RRW joining of Ti6Al4V parts with Ni/Al multilayers as a filler material, carried out at the temperatures below $\alpha \rightarrow \beta$ transition point for Ti6A14V alloy, results in significant decrease of the contamination level as compared with welding techniques.

\section{CONCLUSIONS}

The RRW joining of elements made of Ti6Al4V using $\mathrm{Ni}(\mathrm{V}) / \mathrm{Al}$ multilayers as a filler material was successfully performed by maintaining a DC electric current of $400 \mathrm{~A}$ for at least a few minutes. The following shear tests supported by detailed microstructure observations of the fractured samples allowed to conclude that:

1. Shear strength of the Ti6Al4V/(Ni/Al)/Ti6Al4V joints increased from $\sim 240$ to $\sim 335 \mathrm{MPa}$ as the RRW time was extended from 2 to 6 minutes.

2. De-cohesion of the Ti6Al4V/(Ni/Al)/Ti6Al4V joints during shear stress test occurred within the diffusion zone between the NiAl filler and the Ti6Al4V base alloy.

3. Fracture surfaces of the shear tested samples show mostly flat surfaces with minor amount of material pulled out from the adjacent Ti6Al4V platelets, evidencing a quasi-brittle cracking with some contribution of plastic deformation.
The mechanical and microstructure data obtained in this work demonstrate that the RRW method proposed for joining of TiAl4V components is capable of producing strong joints in relatively short time.

\section{ACKNOWLEDGMENTS}

The investigations were financially supported by the statutory funds of Institute of Metallurgy and Materials Science, PAS (Z-14) and AGH UST No. 11.11.160.438. Microstructure investigations and mechanical tests were performed in the Accredited Testing Laboratories at the Institute of Metallurgy and Materials Science, PAS. The reactive resistive joining experiments were done at the Functional Coatings Lab, Faculty of Materials Science and Ceramics, AGH UST.

\section{OPEN ACCESS}

This article is distributed under the terms of the Creative Commons Attribution 4.0 International License (http://creativecommons.org/licenses/by/4.0/), which permits unrestricted use, distribution, and reproduction in any medium, provided you give appropriate credit to the original author(s) and the source, provide a link to the Creative Commons license, and indicate if changes were made.

\section{REFERENCES}

1. Y. Deng, Q. Guan, B. Wu, and J. Tao: Vacuum, 2015, vol. 117, pp. 17-22.

2. S. Jidhav, A. Powar, S. Patil, A. Supare, B. Farane, and R. Singh: IOP Conf. Series, 2017, vol. 201, p. 012035.

3. F.A. Calvo, J.M. Gomez de Salazar, D. Urena, J.G. Carrion, and F. Perosanz: J. Mater. Sci., 1992, vol. 27, pp. 391-98.

4. D.P. Adams: Thin Solid Films, 2015, vol. 576, pp. 98-128.

5. A. Duckham, S.J. Spey, J. Wang, M.E. Reiss, T.P. Weihs, E. Besnoin, and O.M. Knio: J. Appl. Phys., 2004, vol. 96 (4), pp. $2336-42$.

6. Ł. Maj, K. Mars, J. Morgiel, and E. Godlewska: Phys. Stat. Solidi, 2017, vol. 11 (2), p. 1600405.

7. A.S. Mukasyan and J.D.E. White: Int. J. SHS, 2007, vol. 16 (3), pp. 154-68.

8. Ł. Maj, J. Morgiel, K. Mars, J. Grzegorek, M. Faryna, and E. Godlewska: J. Mater. Process. Technol., 2018, vol. 255, pp. 689-95.

9. A.R. McAndrew, P.A. Colegrove, C. Bühr, B.C.D. Flipo, and A. Vairis: Progr. Mater. Sci., 2018, vol. 92, pp. 225-57.

10. S. Simoes, F. Viana, V. Ventzke, M. Kocak, A.S. Ramos, M.T. Vieira, and M.F. Vieira: J. Mater. Sci., 2010, vol. 45, pp. 4351-57.

11. S. Simoes, F. Viana, and M.F. Vieira: J. Mater. Eng. Perform., 2014, vol. 23, pp. $1536-43$

12. J.P. Oliveira, B. Panton, Z. Zeng, C.M. Andrei, Y. Zhou, R.M. Miranda, and F.M. Braz Fernandes: Acta Mater., 2016, vol. 105, pp. $9-15$. 